\title{
Dir Siluluermultum!
}

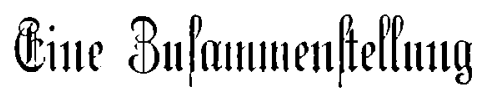

ber

\section{amflichent ayexoxsmungen} fiin:

Edhulamts̆tambionten, $\mathfrak{E e h r e r}$

$\mathfrak{H e x a} \mathfrak{s} \mathfrak{g} \mathfrak{e g e b} \mathfrak{c}$

volt

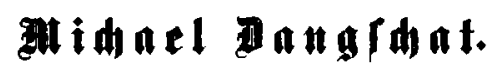

\$ojen, 1884 .

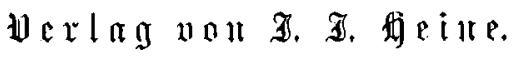


